\title{
ANÁLISE DA QUALIDADE AMBIENTAL DA ÁREA DE EXPANSÃO DE UBERABA-MG NA MICROBACIA DO RIBEIRÃO CONQUISTINHA
}

\author{
Marcos Fernandes Silva ${ }^{1}$ \\ Patrícia Diniz Martins ${ }^{2}$
}

Ana Paula Milla dos Santos ${ }^{3}$

\begin{abstract}
RESUMO
O estudo foi realizado na microbacia do Ribeirão Conquistinha localizada na área de expansão de Uberaba. Foi utilizado para essa análise o emprego de tabelas de aplicação rápidas in situ do Índice de Análise Ambiental Simplificado e parâmetros físicos, dividindo em 15 pontos de amostragem distribuídos no Ribeirão Conquistinha, Ribeirão Três Córregos, Córrego Desbarrancado, Córrego Sucurri, Córrego Pegui. Como resultado foi obtido que, tanto pelo IAAS quanto pelos parâmetros físicos analisados, a maior parcela dos corpos hídricos da microbacia se encontra sobre impacto variando de baixo a médio, com a maior parte tendendo a médio impacto. Os pontos problemáticos detectados foram no Córrego Desbarrancado que recebe alta carga orgânica proveniente dos efluentes domésticos lançados pela rede coletora da cidade que impõe alto impacto na qualidade das águas. Quando esse córrego deságua no Ribeirão Conquistinha ocorre à queda da qualidade desse corpo hídrico que após certo percurso passa por um processo de reareação das águas antes de chegar ao Rio Grande. A maior parte do impacto gerado na área é dado por atividades referentes às ações antrópicas, havendo a necessidade da aplicação de uma educação ambiental no sentido de se evitar os lançamentos clandestinos na área e a conclusão do sistema de coleta de efluente que conduzirá os efluentes lançados no Córrego Desbarrancado até a ETE Conquistinha. Espera-se com estas medidas que a qualidade das águas da microbacia em estudo melhore podendo ser aproveitado seu potencial hídrico para diversas atividades.
\end{abstract}

PALAVRAS-CHAVE: Análise Ambiental Simplificada. Poluição. Qualidade Ambiental.

\footnotetext{
${ }^{1}$ Graduando em Engenharia Ambiental, UFTM, markimfsv@hotmail.com

${ }^{2}$ Engenharia Ambiental, MSc em Recursos Hídricos e Energéticos Ambientais pela Unicamp, docente no curso de Engenharia Ambiental na UFTM, patrícia_ambiental@hotmail.com

${ }^{3}$ Bióloga, Dra em Ciências pela USP, docente no curso de Engenharia Ambiental na UFTM, ana.santos@icte.uftm.edu.br
} 


\title{
ANALYSIS OF ENVIRONMENTAL QUALITY OF THE UBERABA EXPANSION AREA IN THE CONQUISTINHA CREEK WATERSHED.
}

\begin{abstract}
The study was conducted in the Conquistinha Creek watershed located in the expansion area of Uberaba. Was been used for this analysis the rapid application tables in situ of the Simplified Environmental Analysis Index and physical parameters, dividing by 15 sampling points distributed in the Conquistinha Creek, TrêsCórregos Creek, Desbarrancado Creek, Sucurri Creek andPegui Creek. As a result of the SEAI and of the physical parameters, the largest share of water on the watershed is about impact ranging from low to medium, with most tending to medium impact. The trouble spots were detected in Desbarrancado Creek that receives high organic load from domestic effluents discharged by sewage city system that imposes high impact on water quality. When this creek flows into the Conquistinha Creek is the quality of that water decline and after a certain way that goes through a process of waters reaeration before reaching the Grande River. Most of the generated impact in the area is given by activities relating to human actions, necessitating the implementation of environmental education in order to prevent illegal area entries and the conclusion of the wastewater system that will lead the Desbarrancado Creek effluents to ETE Conquistinha. It is hoped that with these actions the water quality of the watershed under study can be exploited to improve its water potential for many activities.
\end{abstract}

KEY WORDS:Simplified Environmental Analysis. Pollution.Environmental Quality.

\section{ANÁLISIS DE LA CALIDAD AMBIENTAL DEL ÁREA DE EXPANSIÓN DE UBERABA-MG EN LA CUENCA DE LA RIVERA CONQUISTINHA.}

\begin{abstract}
RESUMEN
Un estudio fue realizado en la cuenca de la Rivera de Conquistinha, localizada en el área de expansión de Uberaba. Fue utilizado para ese análisis o empleo de tablas de aplicación rápidas in situ del Índice de Análisis Ambiental Simplificado y parámetros físicos, dividiendo en quince puntos de muestreo distribuidos en la Rivera Conquistinha, Rivera Tres Arroyos, Arroyo Desbarrancado, Arroyo Sucurrí, Arroyo Pegui. Como resultado fue obtenido que tanto por el IAAS como por los parámetros físicos analizados, la mayor parte de los cuerpos de agua de la cuenca son sobre el impacto que van desde bajo a medio, con una mayor parte tendiendo a medio impacto. Los puntos problemáticos detectados eran del arroyo desbarrancado que recibe una alta carga orgánica proveniente de dos efluentes domesticas lanzadas por la red colectora de la ciudad que impone un alto impactico en la calidad de las aguas. Cuando ese arroyo de desemboca en el Rivera Conquistinha ocurre que queda la calidad de ese cuerpo hídrico que después de una cierta ruta pasa por un proceso de recreación de las aguas antes de llegar a Rio Grande. Una mayor parte del impacto generado en el área es dado por las actividades referentes a las acciones antrópicas, hallando la necesidad de la aplicación de una educación ambiental, con el fin de evitar los lanzamientos clandestinos en el área de una conclusión
\end{abstract}


del sistema de colección de efluente que conducirá los efluentes puestos en marcha en el arroyo desbarrancado en la Estación de Tratamiento de Efluentes-Conquistinha, se espera que la calidad de las aguas de la cuenca en estudio mejoren pudiendo ser aprovechadas en su potencial hídrico para diversas actividades.

PALABRAS-CLAVE: Conquistinha. Contaminación. Corriente desbordada.

\section{INTRODUÇÃO}

O desenvolvimento de uma cidade impõe sobre o meio ambiente diversos impactos pelo seu crescimento como a supressão de vegetação para construção das novas moradias, impactos na fauna que reside no local, contaminação do solo e dos corpos hídricos principalmente pelo lançamento de esgotos in natura (TUCCl, 2008).

Quando uma cidade se desenvolve dentro de uma única bacia hidrográfica o gerenciamento da coleta de efluentes é de mais fácil execução, pois na maioria das vezes existirá uma única estação de tratamento de efluentes (ETE) para tratar todo o volume coletado sendo desnecessária a instalação, por exemplo, de estações elevatórias para bombear o esgoto para vencer uma cota de terreno dado principalmente por um divisor de bacias.

No caso da área urbana da cidade ocupar mais de uma bacia, normalmente é necessária a instalação de mecanismos complementares do sistema de tratamento de efluentes como, por exemplo, instalação de mais de uma ETE, estações elevatórias, entre outras. Quando se opta pela instalação de mais de uma ETE, normalmente o processo de instalação é feito por etapas, sendo realizado primeiro a que consegue fornecer o serviço para a maior parte da população, para que não ocorra a sobrecarga do sistema de tratamento sem prejudicar o desenvolvimento da cidade.

Em Uberaba, o sistema de tratamento de efluentes é composto por três ETE's: Francisco Veludo, com capacidade de tratamento de $74 \%$ do volume coletado; Filomena Cartafina, com capacidade de $2 \%$ e Conquistinha, com capacidade de $22 \%$. A ETE Conquistinha, ainda em etapa de conclusão, não está em operação e localizase na bacia do Rio Grande, mais especificamente na Microbacia do Ribeirão 
Conquistinha. Os efluentes, que serão tratados por ela, são lançados in natura nos corpos hídricos que compõe essa microbacia.

A Prefeitura Municipal de Uberaba (PMU) tem realizado inúmeros investimentos na área, denominada área de expansão de Uberaba, onde estão sendo construídos vários conjuntos habitacionais do programa 'Minha casa, Minha vida'. Porém, esse progresso tem aumentado o impacto principalmente pelo aumento da carga orgânica e sedimentos nos corpos hídricos da área. O presente trabalho teve com objetivo, a análise e reconhecimento da qualidade ambiental dos corpos hídricos da microbacia do Ribeirão Conquistinha por meio da aplicação do IAAS (Índice de Análise Ambiental Simplificada) e análise de parâmetros como oxigênio dissolvido, condutividade elétrica e $\mathrm{pH}$ dos pontos críticos.

\section{MATERIAL E MÉTODOS}

\section{1 Área de estudo}

A área de estudo está localizada na cidade de Uberaba, estado de Minas Gerais cuja posição geográfica é $19^{\circ} 45^{\prime} 27^{\prime \prime}$ latitude sul e $47^{\circ} 55^{\prime} 36^{\prime \prime}$ longitude oeste. A área superficial do município é de 4.540,51 km² com o perímetro urbano de $256 \mathrm{~km}^{2}$.

O estudo abrangeu a microbacia do Ribeirão Conquistinha que está localizada na área de expansão da área urbana de Uberaba, onde se encontram em fase de conclusão as obras da ETE - Conquistinha.

O Córrego Desbarrancado é o principal contribuinte da bacia e, como o próprio nome diz, sofre com a erosão das suas encostas, sendo vulnerável às grandes vazões. Sua nascente localiza-se dentro do perímetro urbano. Deságua no Ribeirão Conquistinha, que contribui para as vazões do Rio Grande, um possível ponto de captação futura de água do município. Porém o referido córrego recebe a maior parte dos efluentes lançados in natura e apresenta uma alta carga orgânica apresentando características de forte degradação ambiental. 
Segundo o sistema de Köppen, a região do município Uberaba, onde a microbacia está localizada, está submetida a um clima tropical chuvoso do tipo Aw, ou seja, de inverno seco e verão úmido. As estações são bem definidas, apresentando clima frio e seco durante o inverno e clima quente e úmido durante o verão.

A precipitação média mensal é de $130,25 \mathrm{~mm}$, sendo dezembro o mês mais chuvoso com $276 \mathrm{~mm}$ e agosto o menos chuvoso com $11 \mathrm{~mm}$. A vegetação original era constituída por cerrado, cerradão e campo cerrado, atualmente restritas a uma estreita faixa descontínua às margens do curso do Córrego das Lajes, já próximo ao exutório com o Rio Uberaba.

\subsection{Coleta de dados}

As coletas de dados foram feitas no período de agosto de 2013 a maio de 2014, em 15 pontos distribuídos nos seguintes corpos hídricos: Ribeirão Três Córregos (TC); Ribeirão Conquistinha (C); Córrego Desbarrancado (D); Córrego Sucuri (S); Córrego Pequi (P) e, em dois afluentes pequenos (A1 e A2) (Figura 1). 
Figura 1. Área de Estudo da Microbacia do Ribeirão Conquistinha

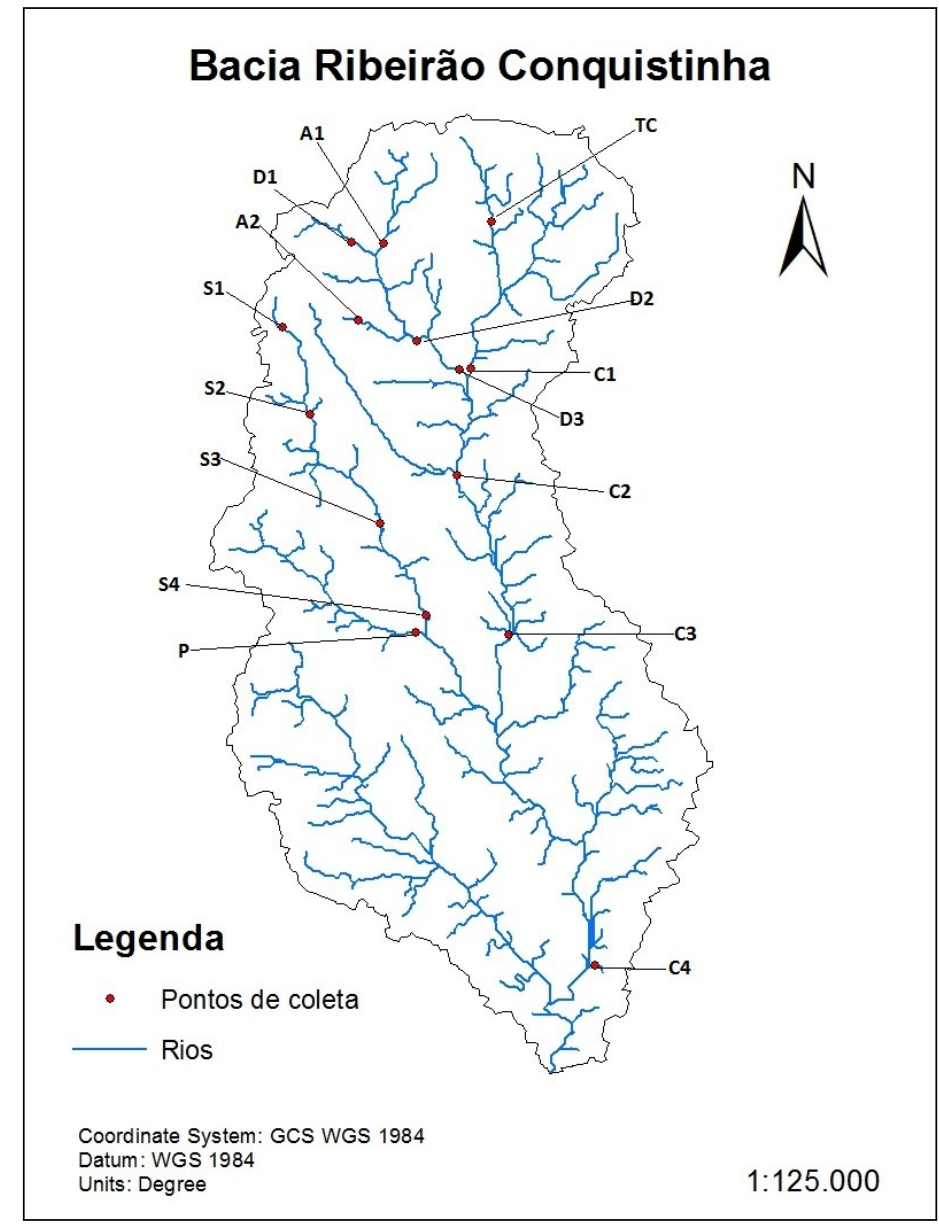

Fonte: Autores, 2014.

\subsubsection{Caracterização fisiográfica da área de estudo}

Com a finalidade de subsidiar os elementos fisiográficos necessários e espacializar as informações resultantes, foram confeccionadas cartas descritivas e interpretativas em meio digital. Este material foi obtido a partir de fotografias aéreas, imagens de satélite e documentos cartográficos existentes, além de controle em campo. O levantamento de campo para a tomada de coordenadas geográficas foi feito utilizando equipamento GPS (Global Positioning System) e Trex Vista H da Garmin. 
Para análise do uso e ocupação do solo da microbacia do Ribeirão Conquistinha, os pontos de amostragem foram observados, em campo, e caracterizados quanto ao tipo de impacto presente predominante: poluição urbana, agropecuária ou industrial e quanto à presença de mata ciliar, protegendo o corpo hídrico.

\subsubsection{Aplicação do IAAS}

Os dados foram coletados por observações em cada ponto de amostragem e preenchimento de planilhas (Tabela 1), sendo distribuídos pesos de 0 a 3 para cada intensidade de impacto, sendo que maiores valores representavam o ambiente menos impactado (Tabela 2).

Tabela 1. Planilha de campo utilizada para aplicação do IAAS

TABELA DE CAMPO DO ÍNDICE DE ANÁLISE AMBIENTAL SIMPLIFICADA (IAAS)

\begin{tabular}{c|c|c|c}
\hline INDICADORES BIOFÍSICOS & PESO & INDICADORES BIOFÍsICOS & PESO \\
\hline Erosão no entorno & & Odor & \\
\hline Boçoroca & $\mathbf{0}$ & Muito forte & $\mathbf{0}$ \\
\hline Sulco & $\mathbf{1}$ & Forte & $\mathbf{2}$ \\
\hline Ravina & $\mathbf{2}$ & Fraco & $\mathbf{3}$ \\
\hline Sem erosão & $\mathbf{3}$ & Ausente & $\mathbf{0}$ \\
\hline Impactos na vegetação & $\mathbf{0}$ & Muito alto & $\mathbf{1}$ \\
\hline $\begin{array}{c}\text { Muito impacto (10\% de vegetação) } \\
\text { Médio impacto (-50\% da } \\
\text { vegetação) }\end{array}$ & $\mathbf{1}$ & Alto & $\mathbf{2}$ \\
\hline $\begin{array}{c}\text { Pouco impacto (+50\% da } \\
\text { vegetação) }\end{array}$ & $\mathbf{2}$ & Baixo & $\mathbf{3}$ \\
\hline Sem impacto & $\mathbf{3}$ & Não detectado & $\mathbf{0}$ \\
\hline $\begin{array}{c}\text { Fauna no entorno } \\
\text { Ausência de animais nativos }\end{array}$ & $\mathbf{0}$ & Espumas & $\mathbf{1}$ \\
\hline Pouca presença animais nativos & $\mathbf{1}$ & Muito alta & $\mathbf{2}$ \\
\hline $\begin{array}{c}\text { Moderada presença animais } \\
\text { nativos }\end{array}$ & $\mathbf{2}$ & Alta & $\mathbf{3}$ \\
\hline $\begin{array}{c}\text { Grande presença de animais } \\
\text { nativos }\end{array}$ & $\mathbf{3}$ & Baixa & \\
\hline \begin{tabular}{c} 
Saneamento \\
\hline
\end{tabular} & & Ausente & Algas / clorofila \\
\hline
\end{tabular}




\begin{tabular}{c|c|c|c}
\hline Efluente lançados in natura & $\mathbf{0}$ & Muito alto & $\mathbf{0}$ \\
\hline Dejetos ou urina & $\mathbf{1}$ & Alto & $\mathbf{1}$ \\
\hline Entulhos lixo & $\mathbf{2}$ & Baixo & $\mathbf{2}$ \\
\hline $\begin{array}{c}\text { Saneamento adequado } \\
\text { Lixo no entorno do recurso } \\
\text { hídrico }\end{array}$ & $\mathbf{3}$ & Ausente & $\mathbf{3}$ \\
\hline Muito lixo & $\mathbf{0}$ & Larvas e vermes vermelhos & \\
\hline Pouco lixo & $\mathbf{1}$ & Muito alta & $\mathbf{0}$ \\
\hline Lixo em latões & $\mathbf{2}$ & Alta & $\mathbf{1}$ \\
\hline Ausência & $\mathbf{3}$ & Baixa & $\mathbf{2}$ \\
\hline Turbidez da água & & Erosão das Margens & $\mathbf{3}$ \\
\hline Muito alta & $\mathbf{0}$ & Muito Alta & $\mathbf{0}$ \\
\hline Alta & $\mathbf{1}$ & Alta & $\mathbf{1}$ \\
\hline Baixa & $\mathbf{2}$ & Baixa & $\mathbf{2}$ \\
\hline Ausente & $\mathbf{3}$ & Ausente & $\mathbf{3}$ \\
\hline 2014.
\end{tabular}

Fonte: Autores, 2014.

Tabela 2. Pesos de avaliação usados no IAAS

\begin{tabular}{c|c}
\hline \multicolumn{2}{c}{ Índice de Análise Ambiental Simplificado (IAAS) } \\
\hline Peso do Impacto & Tipo de Impacto \\
\hline 0 & Ausente \\
\hline 1 & Baixo \\
\hline 2 & Médio \\
\hline 3 & Alto \\
\hline
\end{tabular}

Fonte: Autores, 2014.

O IAAS foi calculado pela somatória dos pesos de cada parâmetro. Cada ponto de amostragem foi analisado quanto ao grau do impacto de acordo com a escala de classificação apresentada na Tabela 3.

Tabela 3. Escala de classificação dos resultados do IAAS

\begin{tabular}{|c|c|}
\hline \multicolumn{2}{|c|}{ FAIXA DE DISTRIBUIÇÃO DO IMPACTO DADO PELO IAAS } \\
\hline GRAU DO IMPACTO & FAIXA DE ANÁLISE \\
\hline Extremamente Alto & $0-10$ \\
\hline Alto & $11-20$ \\
\hline Médio & $21-30$ \\
\hline Baixo & $31-36$ \\
\hline
\end{tabular}

Fonte: Autores, 2014. 


\subsubsection{Parâmetros físico-químicos}

Como grande parte de córregos da microbacia possui um volume pequeno de água escoando por seus leitos, o método de caracterização da vazão utilizado foi o 'método do objeto flutuador'. Esse processo consiste na determinação da velocidade de um objeto flutuador sobre os rios, sendo então a velocidade do rio igual à do objeto. Para isso o objeto adotado não pode possuir um peso elevado, pois ocorreria o acúmulo de erros na amostragem.

Em seguida, a área da seção transversal do rio foi determinada pela batimetria do leito do rio. Em rios muito irregulares o espaçamento da amostragem utilizado foi menor, a fim de tentar diminuir os erros de cálculo dessa área, que afetam diretamente os valores de vazões a serem transportados por cada corpo hídrico.

Os parâmetros de oxigênio dissolvido, condutividade elétrica, temperatura e pH foram medidos por sonda multiparâmetros. $\mathrm{O}$ processo de medição ocorreu pela inserção do leitor da sonda no corpo hídrico, na seção de maior deslocamento de fluido, para garantir uma amostra homogênea, e leitura após a estabilização dos valores.

\section{RESULTADOS E DISCUSSÃO}

\subsection{Caracterização fisiográfica da área de estudo}

Como é possível analisar, a área de expansão está sobre influencia principalmente de atividades relacionadas à criação de gado, atividades antrópicas e áreas de cultivo. Dentre essas três categorias, apesar da área de influência do meio urbano ser ao menor, ele é o que impõe o maior impacto na área, principalmente pelo lançamento de esgotos no Córrego Desbarrancado (pontos D1, D2 e D3). 
Figura 2. Distribuição da frequência de atividades relacionadas aos pontos de coleta

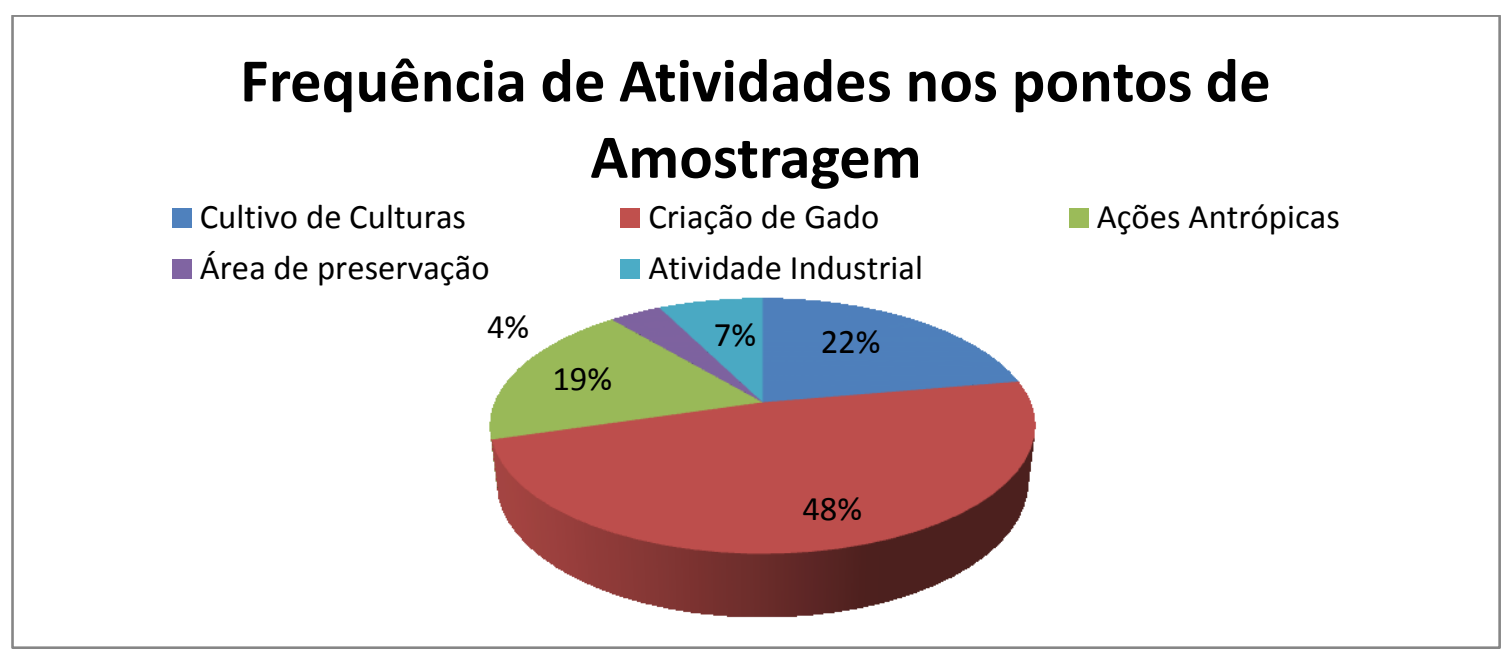

Fonte: Autores, 2014.

As atividades relacionadas ao cultivo de grãos e à criação de gado são extremamente fortes em Uberaba, conhecida como capital nacional do agronegócio, possuindo várias linhas de financiamento para seu o desenvolvimento e forte mercado consumidor e exportador.

Devido a essa demanda do mercado, grandes áreas são desmatadas para o processo de cultivo das culturas e para a criação do gado gerando impactos diretos nos solos e nos corpos hídricos da microbacia do Ribeirão Conquistinha.

A Figura 3 apresenta as características da microbacia do Ribeirão Conquistinha, quanto ao uso e a ocupação do solo. As análises foram feitas no laboratório de Geoprocessamento do Instituto de Ciências Tecnológicas e Exatas (ICTE) da Universidade Federal do Triângulo Mineiro (UFTM), por meio do software ArcGis-10.1, utilizando imagens do Instituto Nacional de Pesquisas Espaciais (INPE). 
Figura 3. Características do uso e ocupação do solo da microbacia do Ribeirão Conquistinha

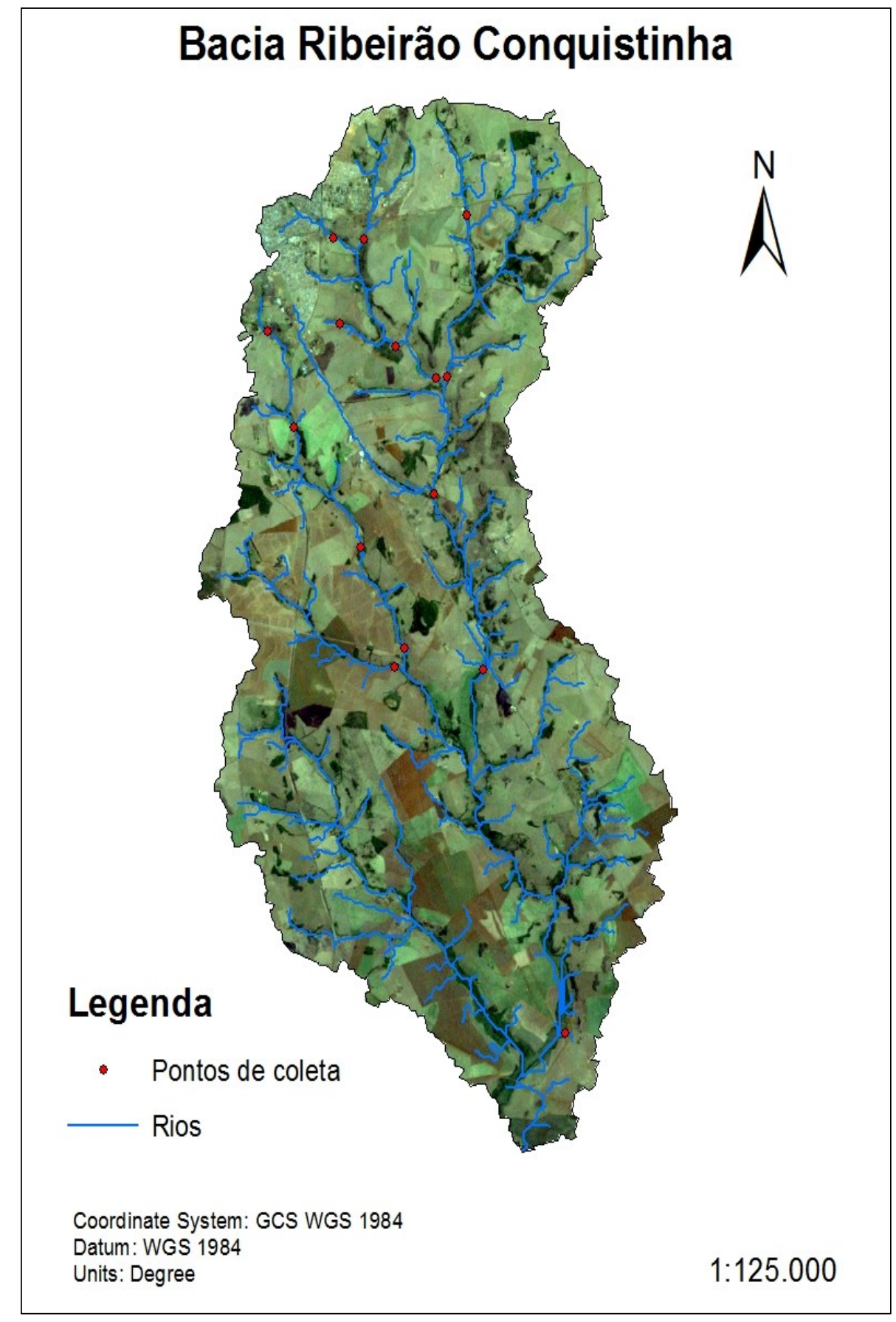

Fonte: Autores, 2014.

\subsection{Aplicação do IAAS}


Aplicando a planilha de campo descrita na Tabela 2 foram obtidos os seguintes resultados:

Tabela 4. Resultados do IAAS

\section{Resultados obtidos pela aplicação do IAAS na microbacia do Ribeirão Conquistinha}

\begin{tabular}{c|c|c}
\hline Ponto de Amostragem & $\begin{array}{c}\text { Resultado do } \\
\text { IAAS }\end{array}$ & Impacto \\
\hline (Ribeirão Três Coórregos, Ponto único) - TC & 28 & Médio \\
\hline (Afluente Sem nome 01) - A1 & 22 & Médio \\
\hline (Afluente Sem nome 02) - A2 & 24 & Médio \\
\hline (Córrego Desbarrancado, Ponto 01) - D1 & 12 & Alto \\
\hline (Córrego Desbarrancado, Ponto 02) - D2 & 13 & Alto \\
\hline (Córrego Desbarrancado, Ponto 03) - D3 & 08 & Alto \\
\hline (Córrego Sucurri, Ponto 01) - S1 & 26 & Médio \\
\hline (Córrego Sucurri, Ponto 02) - S2 & 30 & Médio \\
\hline (Córrego Sucurri, Ponto 03) - S3 & 27 & Médio \\
\hline (Córrego Sucurri, Ponto 04) - S4 & 27 & Médio \\
\hline (Córrego Pequi, Ponto único) - P & 26 & Médio \\
\hline (Ribeirão Conquistinha, Ponto 01) - C1 & 23 & Médio \\
\hline (Ribeirão Conquistinha, Ponto 02) - C2 & 20 & Médio \\
\hline (Ribeirão Conquistinha, Ponto 03) - C3 & 25 & Médio \\
\hline (Ribeirão Conquistinha, Ponto 04) - C4 & 29 & \\
\hline
\end{tabular}

Fonte: Autores, 2014.

A seguir está apresentado graficamente na Figura 4 o impacto resultado do IAAS versus sua localidade na microbacia de estudo.

Figura 4. Magnitude do Impacto resultante pela aplicação do IAAS

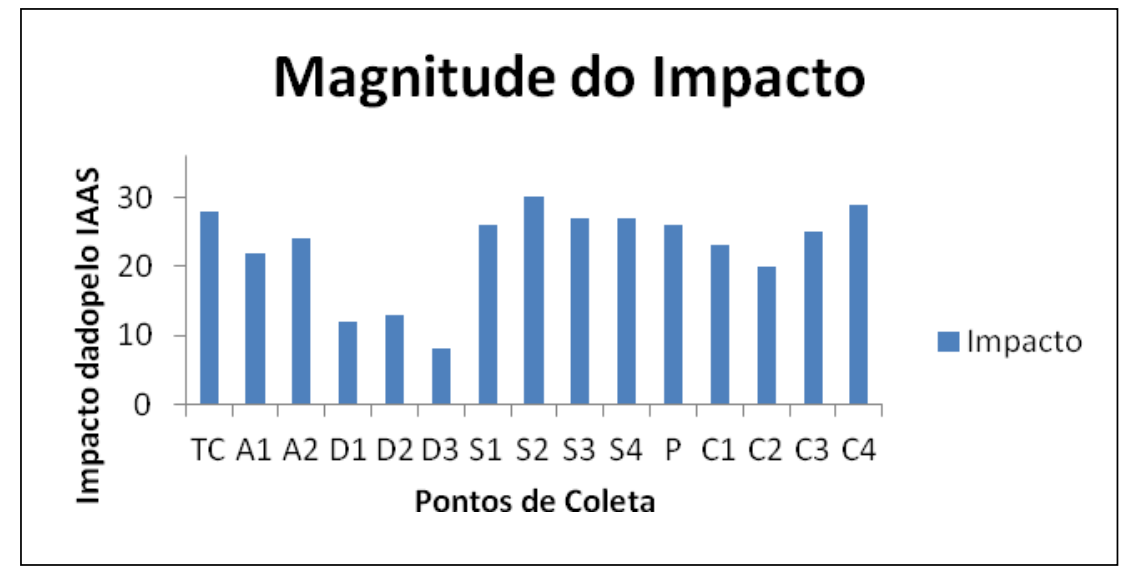

Fonte: Autores, 2014. 


\subsection{Parâmetros físico-químicos}

Os resultados obtidos na sonda multiparâmetros estão apresentados nas Figuras 5 a 8 .

Figura 5. Valores de oxigênio dissolvido obtidos nos pontos de amostragem

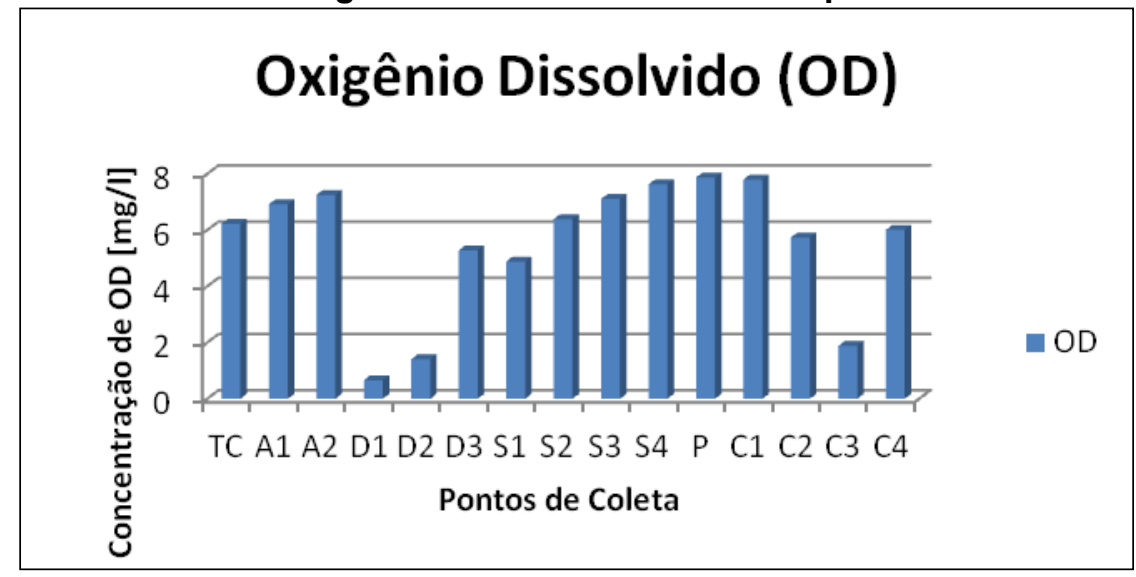

Fonte: Autores, 2014.

Figura 6. Temperatura Obtida nos pontos de amostragem

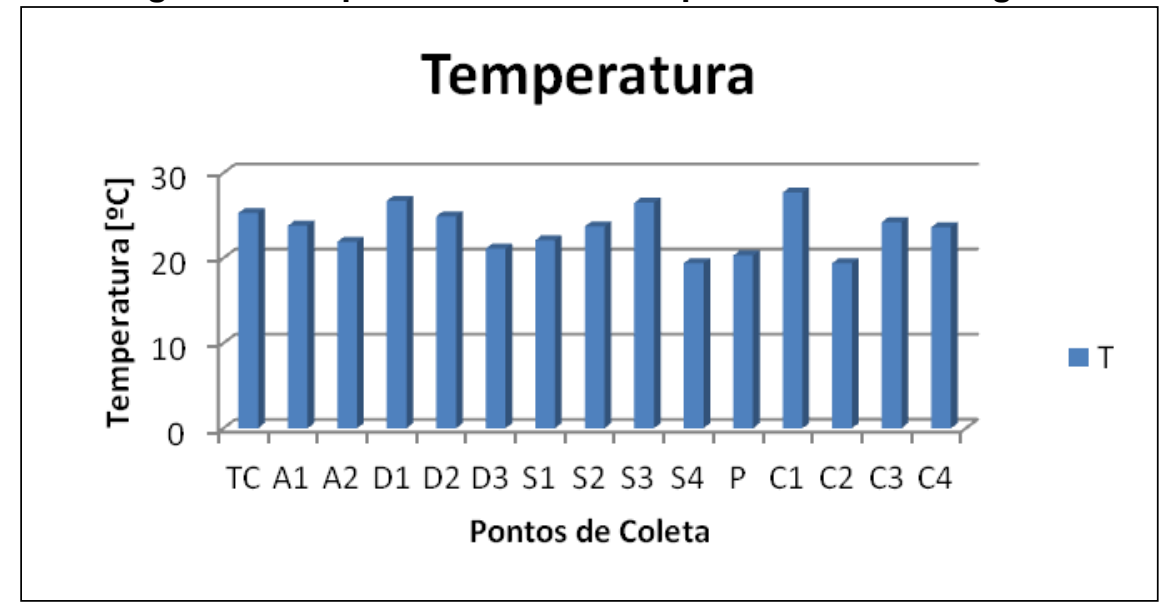

Fonte: Autores, 2014. 
Figura 7. Condutividade Elétrica obtida nos pontos de amostragem

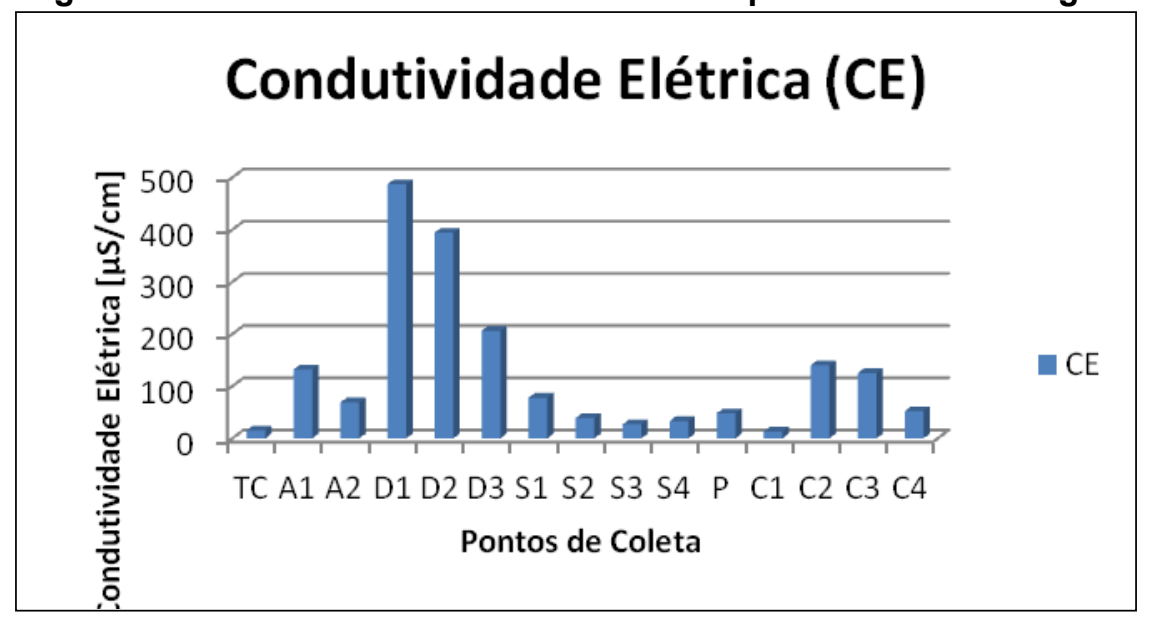

Fonte: Autores, 2014.

Figura 8. Valores de pH obtidos nos pontos de amostragem

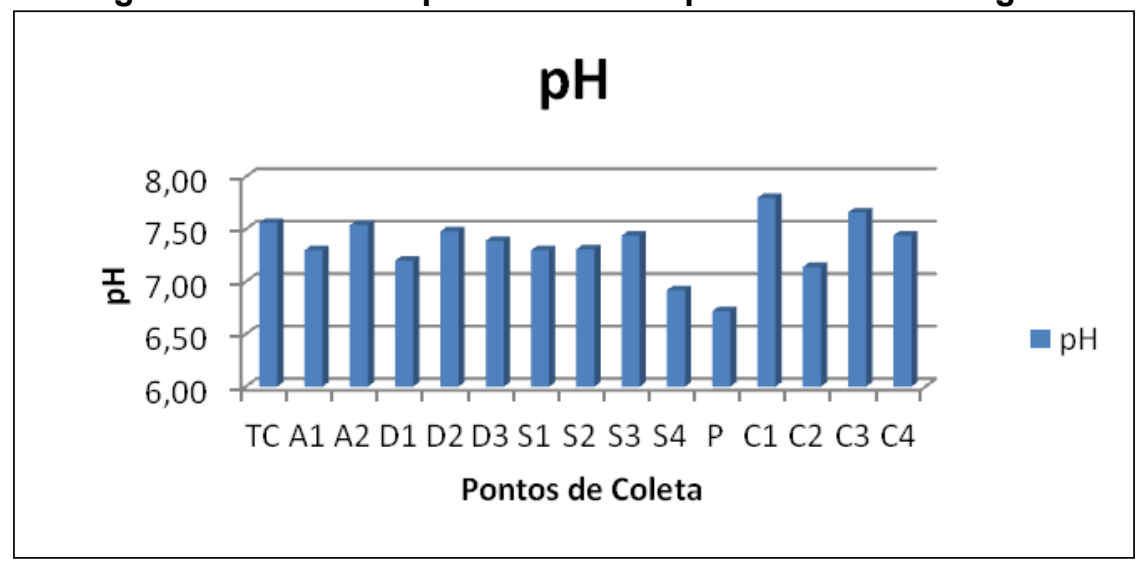

Fonte: Autores, 2014

Fazendo uma análise entre o IAAS obtido e dos parâmetros analisados, temos que o Córrego Desbarrancado é o que possui pior situação de degradação ambiental. O primeiro ponto de coleta (D1) localizado próximo à área urbana apresenta uma alta carga orgânica, que durante a degradação consome praticamente todo oxigênio. Pela bibliografia, água com concentrações de oxigênio dissolvido (OD) abaixo de 2,0 mg/l são características de áreas onde o processo de degradação de matéria orgânica(MO) já consumiu todo $\mathrm{OD}$ presente e então passando a degradar a $\mathrm{MO}$ pelos processos anaeróbicos. Outro parâmetro que indica poluição por material orgânico é dado pela alta condutividade elétrica (CE) do ponto de coleta, que pode 
ser explicada pela quantidade de íons dispersos no efluente que é despejado no córrego alterando sua CE natural. Analisando os outros pontos dispostos no referido corpo hídrico (D2 e D3) é possível ver que o sistema hídrico começa a apresentar um processo de recuperação da qualidade pelo aumento da concentração de OD e amenização da CE.

Em relação ao Ribeirão Três Córregos, Córrego Sucuri, Córrego Pequi pode-se observar pelos parâmetros analisados indicam boa qualidade das águas e quando entrarem em contato com as águas do corpo hídrico principal da calha de drenagem da microbacia eles funcionam como diluídores das concentrações de material orgânico dissolvidos e patogênicos.

Referente ao Ribeirão Conquistinha, que é o principal rio da rede de drenagem da microbacia, é possível notar que o primeiro ponto fica disposto em uma área de pasto e possui alta concentração de OD e baixa CE. Quando as águas do Ribeirão Conquistinha recebem as água do Córrego Desbarrancado ocorre uma queda no oxigênio dissolvido após o ponto de mistura. No ponto de mistura, o Córrego Desbarrancado possui uma carga orgânica maior que as águas do Ribeirão Conquistinha e após o ponto de mistura ocorre à elevação da carga orgânica, sendo então entendido como um ponto de poluição quando ocorre o encontro (PORTO, 2001).

As concentrações de OD continuam a decrescer ate o ponto C3, e a partir desse ponto é possível notar o início do processo de reaeração das águas superficiais feitas principalmente pela influência da pressão atmosférica e da agitação das águas como comprova as concentrações obtidas no ponto C4.

A CE do Ribeirão Conquistinha apresenta também um comportamento condizente com realidade do local. No primeiro ponto apresenta uma condutividade relativamente baixa e após o ponto de mistura com o Córrego Desbarrancado ocorre uma elevação nos valores medidos que vão diminuindo até o último ponto de monitoramento localizado próximo ao exutório da microbacia. Para melhor caracterização estão dispostos nas Figuras 9 a 13 os registros fotográficos de alguns pontos de amostragem. 
Figura 9. Ponto de Coleta A1 (09/10/2013)

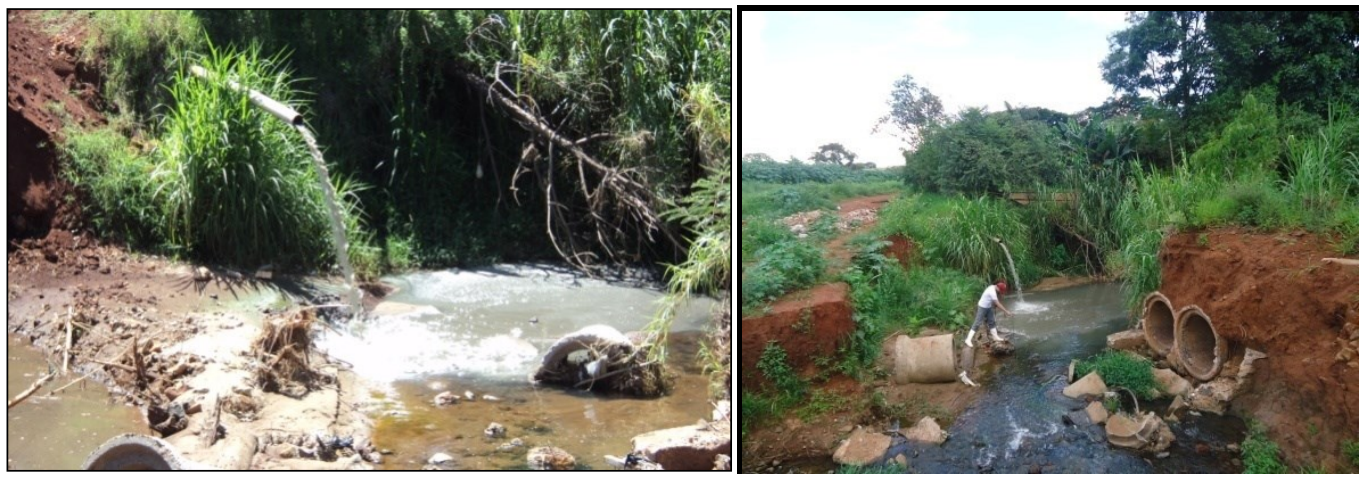

Fonte: Autores, 2014.

Figura 10. Ponto de Coleta D1 (09/10/2013)

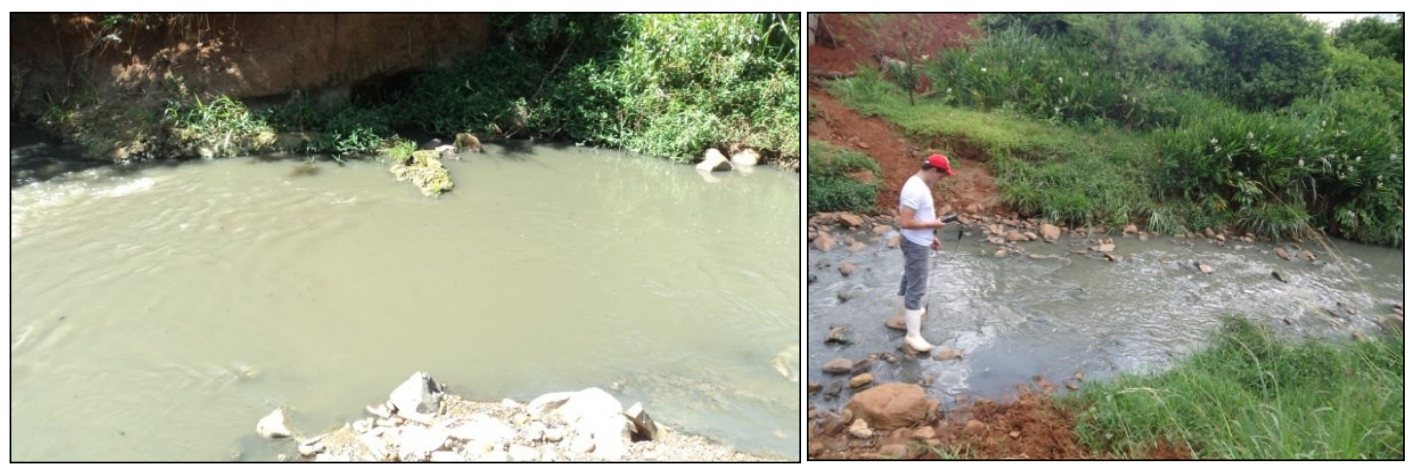

Fonte: Autores, 2014.

Figura 11. Ponto de Coleta D3 (09/10/2013)
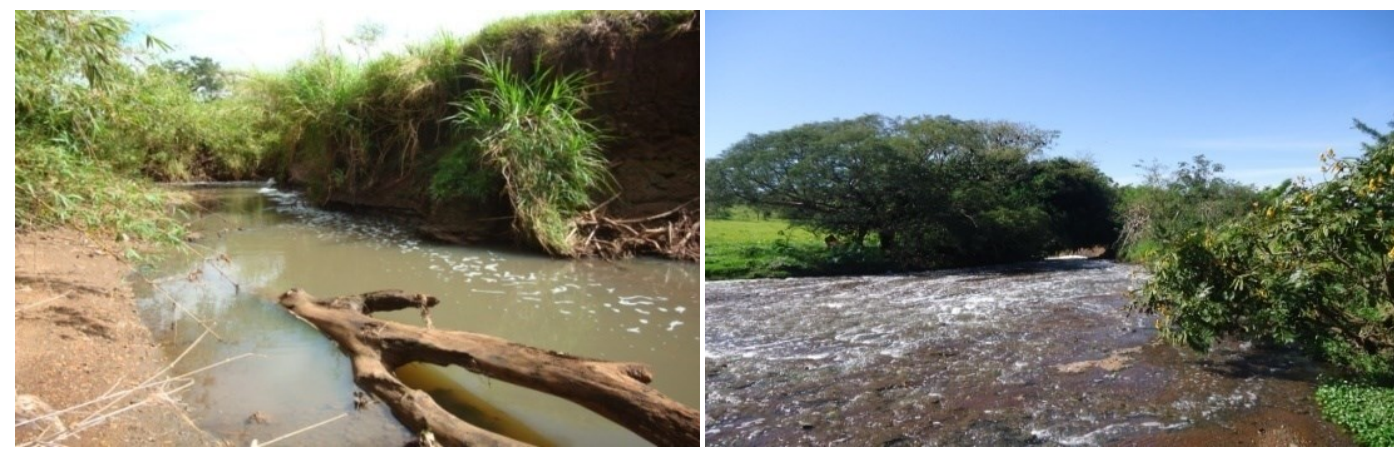

Fonte: Autores, 2014. 
Figura 12. Ponto de Coleta C1 (09/10/2013)
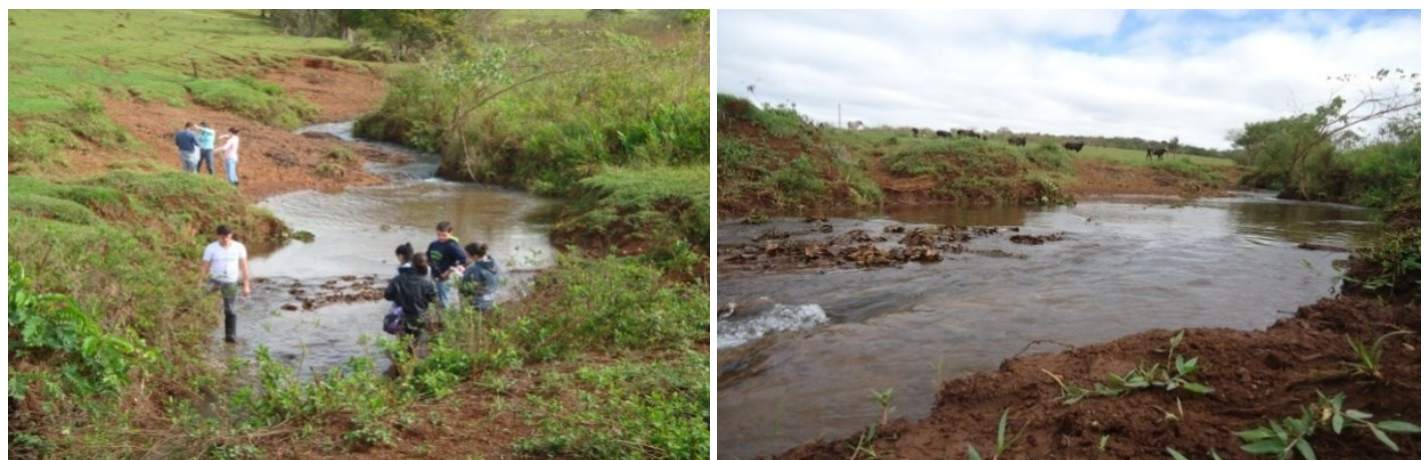

Fonte: Autores, 2014.

Figura 13. Ponto de Coleta C3 ( 09/10/2013)
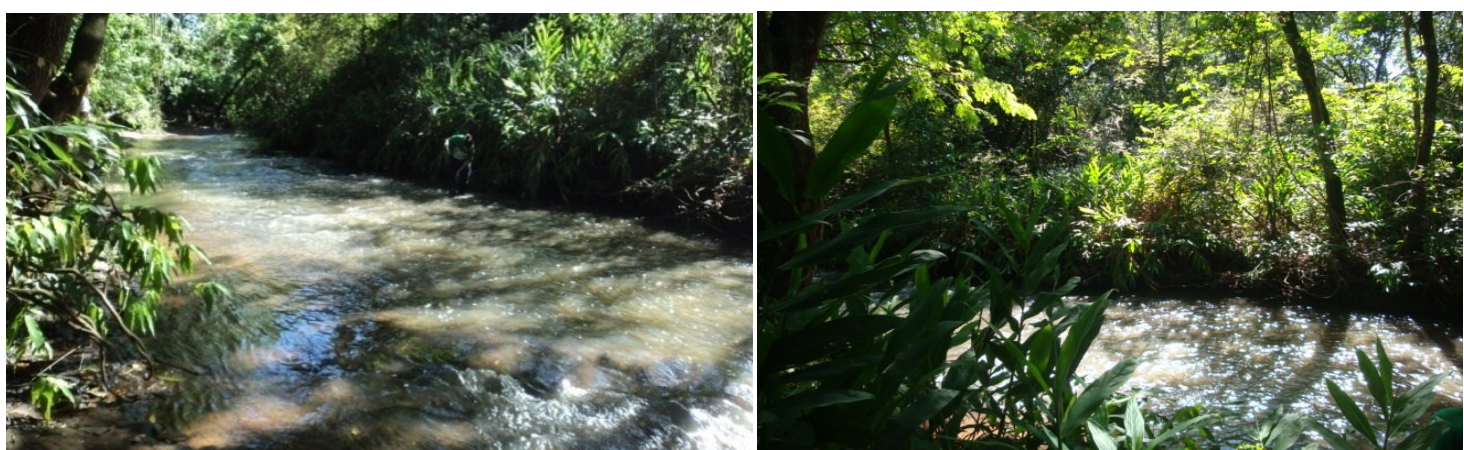

Fonte: Autores, 2014.

\section{CONSIDERAÇÕES FINAIS}

A área de expansão de Uberaba possui grande potencial de desenvolvimento para ocupação da população. É uma área de fácil acesso, podendo ser instalada uma estrutura urbana de qualidade com desenvolvimento planejado pela administração pública municipal.

As ações adotadas na área para minimizar os impactos provocados pela expansão da ocupação são de suma importância para poder conciliar o crescimento com a preservação do local, principalmente dos corpos hídricos presentes no local. A principal obra executada pela PMU é a construção da ETE Conquistinha que está em fase de conclusão das obras e possui capacidade para futuras ampliações. 
No estado atual a área apresenta forte degradação ambiental principalmente no Córrego Desbarrancado pela alta carga orgânica lançada em suas águas. Como o volume desse corpo hídrico é bastante pequeno e o volume de efluente lançados é alto, ele apresenta característica de um sistema que degrada o material orgânico por anaerobiose, pelo baixo fluxo, ocorre à deposição no fundo do leito do rio do material em processo de decomposição.

Para uma melhor efetivação das medidas é necessária uma conscientização da população sobre a preservação ambiental, assim como sobre o despejo clandestino de esgotos nos corpos hídricos, mostrando que essas ações não têm apenas impacto local, mas afetando todos os dependentes da utilização dos corpos hídricos dessa microbacia hidrográfica.

\section{REFERÊNCIAS}

PREFEITURA MUNICIPAL DE UBERABA (PMU). Uberaba em dados. 2009. Disponível em: <http://www.uberaba.mg.gov.br/portal/conteudo,232>. Acesso em: 11 maio 2014.

PREFEITURA MUNICIPAL DE UBERABA (PMU). Relatório ambiental projeto Água Viva: projeto de recuperação ambiental da bacia do Rio Uberaba e revitalização do sistema de abastecimento de água. Uberaba, 2005. $416 \mathrm{p}$.

PORTO, L. L. R.; SILVA, M. R.; ZAHED, F. K. Medição de vazão e curva-chave. Escola Politécnica da Universidade de São Paulo. Departamento de Eng. Hidráulica e Sanitária. São Paulo, 2001. 34p.

TUCCI, C. E. M. Hidrologia: ciência e aplicação. $2^{a}$ ed. Porto Alegre: Editora da Universidade: ABRH, 2008, 40p. 